\title{
SORPTION OF CATIONIC DYES FROM AQUEOUS SOLUTIONS BY MOSS Rhytidiadelphus squarrosus: KINETICS AND EQUILIBRIUM STUDIES
}

\author{
LUCIA REMENÁROVÁ ${ }^{1}$, MARTIN PIPÍŠKA ${ }^{1,2}$, \\ MIROSLAV HORNÍK ${ }^{1,2}$, JOZEF AUGUSTÍN ${ }^{1,2}$ \\ ${ }^{1}$ Department of Biotechnology, University of SS. Cyril and Methodius, J. Herdu 2, \\ Trnava, SK-917 01, Slovak Republic (pipiskam@ucm.sk) \\ ${ }^{2}$ Consortium for Environmental Biotechnology and Environmental Chemistry, \\ Hlavná 418, Špačince, SK-919 51, Slovak Republic
}

\begin{abstract}
With the aim to investigate sorption properties of natural sorbent prepared from moss Rhytidiadelphus squarrosus we elucidated biosorption of cationic dyes Malachite green (BG4), Auramine O (BY2) and Thioflavine T (BY1) from aqueous solutions. The removal of dyes by moss biosorbent was found to be rapid at an initial stage and the equilibrium was reached within 1-2 hours. The pseudo- $n$-order kinetic model was successfully applied to the kinetic data and the order of adsorption reaction was calculated in the range from 1.7 to 2.6 . The value of rate constant $k_{n}{ }^{\prime}$ ranged from 0.001 to $0.039\left[\mathrm{~min}^{-1}\right] /[\mu \mathrm{mol} / \mathrm{g}]^{1-\mathrm{n}}$ The equilibrium data were fitted to the adsorption isotherms. The Freundlich isotherm was found to represent the measured sorption data of BG4, BY1 and BY2 well. The maximum sorption capacities of moss biomass from single dye solutions calculated by Langmuir equation were $354 \mu \mathrm{mol} / \mathrm{g}$ for BG4, $310 \mu \mathrm{mol} / \mathrm{g}$ for BY1 and $382 \mu \mathrm{mol} / \mathrm{g}$ for BY2. These results showed that the prepared biomass presents low-cost, natural and easy available sorbent which may be potentially used for removal of dyes from environment and also may be an alternative to more costly materials such as activated carbon.
\end{abstract}

Key words: Malachite green, Thioflavine T, Auramine O, Rhytidiadelphus squarrosus, sorption kinetics, sorption equilibrium

\section{Introduction}

Contamination of water sources by many organic pollutants is a major factor of global environmental pollution for the number of years. Dyes represent one of the problematic groups. Two main sources of dye pollution are the textile and dyestuff manufacturing industries. Color is the first contaminant to be recognized in wastewater and the presence of very small amounts of dyes in water is highly visible and undesirable (CRINI and BADOT, 2008; IQBAL and ASHIQ, 2007; AKSU, 2005). The presence of synthetic dyes in the aquatic environment has been of great concern because of their potential health hazards associated with the carcinogenic, mutagenic, allergenic and toxic natures as well as negative effects on the photosynthetic activity in aquatic life.

Adsorption techniques employing solid adsorbents are effective methods for water decontamination. Most commercial systems currently use activated carbon and organic resins as adsorbents to remove dye in wastewater because of their excellent adsorption 
abilities. A large variety of non-conventional adsorbent materials have been also proposed and studied for their ability to remove dyes (CRINI, 2006; 2008).

Sorption systems have been investigated to assess their suitability for application in the field of water pollution control. The cost and performance of a product or the mode of application are always of concern to control process efficiency. Therefore the sorption capacity and required contact time are two of the most important parameters to understand (HO et al., 2000).

The aim of this study was to realize biosorption of cationic dyes from aqueous solutions and to consider sorption properties of natural sorbent prepared from moss Rhytidiadelphus squarrosus. Experimental kinetics data were analyzed using a pseudo- $n$-order kinetic equation. The equilibrium data have been analyzed using Langmuir and Freundlich isotherms and the characteristics parameters of each isotherm have been determined.

\section{Materials and methods}

\subsection{Chemicals}

In sorption experiments cationic dyes Malachite green (BG4, Basic green 4 malachite green oxalate, $\mathrm{M}_{\mathrm{r}}$ 927, C.I. 42 000, Merck, D); Auramine O (BY2, Basic Yellow 2, $\mathrm{M}_{\mathrm{r}}$ 304, C.I. 41 000, Aldrich, D) and Thioflavine T (BY1, Basic Yellow 1, $M_{r}$ 319, C.I. 49 005, Fluka, D) were used. The stock solutions of dyes were prepared in deionized water.

\subsection{Biosorbent preparation}

Moss R. squarrosus was collected from forests in High Tatras Mountains, Slovak Republic. Before using in experiments the biomass was thoroughly washed in deionized water, oven-dried for $72 \mathrm{~h}$ at a maximum of $45^{\circ} \mathrm{C}$ to avoid degradation of binding sites and pulverized in blade homogenizer. Size analysis showed the following separation of particles size: $>600 \mu \mathrm{m}-5 \%$; 600-300 $\mu \mathrm{m}-49 \% ;<300 \mu \mathrm{m}-46 \%$. Fraction $<300 \mu \mathrm{m}$ was used in sorption experiments.

\subsection{Sorption kinetics}

Batch sorption experiments were carried out in Erlenmayer flasks containing $20 \mathrm{~mL}$ BG4, BY1 and BY2 solutions with defined concentrations. pH value was adjusted to 4.0 with $0.1 \mathrm{M} \mathrm{HCl}$. Biomass ( $\sim 30$ or $40 \mathrm{mg}$, d.w.) was added and flasks were agitated on a reciprocal shaker $(250 \mathrm{rpm})$ at $25{ }^{\circ} \mathrm{C}$. Samples were taken from individual flasks in intervals 5, 10, 20, 40, 120, 240 and 1440 min and analyzed using Varian Cary 50 UV-VIS spectrophotometer by measuring the optical densities of dyes at their respective maximum absorbance wavelengths. These are 617, 412 and $435 \mathrm{~nm}$ for BG4, BY1 and BY2, respectively. If not otherwise stated, presented data are the arithmetic mean values. 


\subsection{Sorption equilibrium}

All experiments were carried out in Erlenmayer flasks with $20 \mathrm{~mL}$ of BG4, BY1 and BY2 solutions with initial concentration from 50 to $400 \mathrm{mg} / \mathrm{L}$. $\mathrm{pH}$ value was adjusted to 4.0 with $0.1 \mathrm{M} \mathrm{HCl}$. Biomass $(20 \mathrm{mg}$, d.w.) was added and the flasks were agitated on a reciprocal shaker $(250 \mathrm{rpm})$ for $4 \mathrm{~h}$ at $25^{\circ} \mathrm{C}$. At the equilibrium, samples were taken and analyzed spectrophotometrically. If not otherwise stated, presented data are arithmetic mean values.

\subsection{Non-linear regression analysis}

To calculate parameters of pseudo- $n$-order model, the $Q_{\max }$ values and the corresponding parameters of adsorption isotherms non-linear regression analysis was performed by the NLSF (Origin's nonlinear least square fitter) using program MicroCal Origin 8.0 Professional (OriginLab Corporation, Northampton, USA) with automatic initialization of parameters and GraphPad PRISM 5.0 software (GraphPad Software Inc., USA).

\section{Results and discussion}

\subsection{Biosorption kinetics}

The time-course studies on the biosorption of cationic dyes BY1, BY2 and BG4 were performed by contacting the dye solutions with moss biosorbent at $\mathrm{pH} 4.0$ and 25 ${ }^{\circ} \mathrm{C}$. Biosorption of BY1, BY2 and BG4 by $R$. squarrosus is faster at initial stage, during occupation of high affinity sites (Fig. 1.) Maximum uptake, approx. $95 \%$ at biosorbent concentration $2.0 \mathrm{~g} / \mathrm{L}$ and initial BG4 concentration $\mathrm{C}_{0}=122 \mu \mathrm{mol} / \mathrm{L}$ was reached within $60 \mathrm{~min}$. In the case of BY1 $\left(\mathrm{C}_{0}=307 \mu \mathrm{mol} / \mathrm{L}\right)$ and $\mathrm{BY} 2\left(\mathrm{C}_{0}=339\right.$ $\mu \mathrm{mol} / \mathrm{L}$ ) uptake reached aprox. $80 \%$ within the first $90 \mathrm{~min}$ at biosorbent concentration $1.5 \mathrm{~g} / \mathrm{L}$. After this time there was no considerable increase during the next 23 hours. CRINI et al. (2007) also observed a very fast sorption of BG4 by cyclodextrin-based adsorbent. The largest amount of BG4 was adsorbed to the polymer within the first 90 min. Rapid sorption of BY2 by poly-( $\gamma$-glutamic acid) was confirmed by INBARAJN et al. (2006). Maximum sorption was accomplished within $12 \mathrm{~min}$ indicating a rapid surface adsorption of BY2 on poly-( $\gamma$-glutamic acid) occurred.

The mechanism of a short-term dye uptake by biosorbents is generally regarded as an abiotic process. It is known that biomass contains ionogenic groups such as carboxyl, phenolic and alcoholic hydroxyl, and phosphate that generate a negative net charge. Basic dyes can be ionized in solution to form positive charge and chemical reaction through electrostatic interaction may occur between anionic groups of moss biosorbent and cations of dyes molecules (CRINI and PEINDY, 2006).

Biosorption kinetics describing the pollutant uptake rate is one of the important characteristics defining the efficiency of sorption and feasibility of (bio)sorbents for their use in water pollution control. In almost all previous biosorption kinetic studies, 
both pseudo-first (1) and pseudo-second (2) order kinetic equations were directly chosen to fit biosorption data without any explanation about the rational behind.

$$
\begin{gathered}
\frac{d Q_{t}}{d t}=k_{1}^{\prime}\left(Q_{e q}-Q_{t}\right) \\
\frac{d Q_{t}}{d t}=k_{2}^{\prime}\left(Q_{e q}-Q_{t}\right)^{2}
\end{gathered}
$$

LIU and LIU (2008) pointed out that, there is no reason and need to preset biosorption kinetics to be the first or the second order unless biosorption mechanisms are known. Considering the complexity of biosorption process and fact that the various mechanisms would be involved ÖZER (2007) and LIU and WANG (2008) the direct calculation of rate constant and order of the biosorption reaction recommended as a more appropriate method. For these reasons the experimental data obtained by nonequilibrium conditions in our work were analyzed using a pseudo- $n$-order (3) model proposed by ÖZER (2007) and LIU and SHEN (2008):

$$
\frac{d Q_{t}}{d t}=k_{n}^{\prime}\left(Q_{e q}-Q_{t}\right)^{n}
$$

where $n$ is the reaction order determined from biosorption data and $k_{n}$ is a rate constant. The integrated form of equation (3) has the following form:

$$
Q_{t}=Q_{e q}-\left[(n-1) k_{n}^{\prime} t+Q_{e q}{ }^{(1-n)}\right]^{\frac{1}{1-n}}
$$

where $Q_{t}$ is the amount of sorbate sorbed at time $t, Q_{e q}$ represents sorbate sorption at equilibrium.

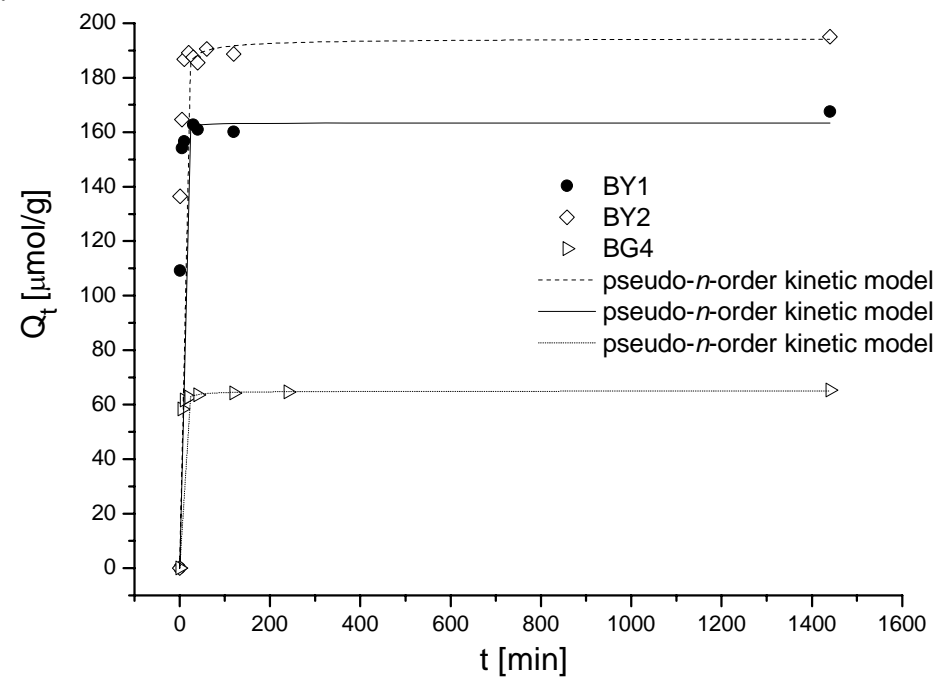

Fig. 1. Kinetics of BY1 $(\bullet)$, BY2 $(\diamond)$ and BG4 $(\triangleright)$ biosorption by $R$. squarrosus at pH 4 and $25{ }^{\circ} \mathrm{C}$. Experimental data fitted to pseudo- $n$-order kinetic model. Data shown in Table 1. 
Plot of pseudo- $n$-order kinetics model (4) for the biosorption of dyes by moss biosorbent is shown in Fig. 1. The model parameters determined by non-linear regression analysis are shown in Table 1 . The calculated $Q_{\text {eq cal }}$ values from the model are in good agreement with experimental $Q_{\text {eq exp }}$ values and the correlation coefficients for the pseudo- $n$-order kinetic plots are very high. The respective reaction order for BG4, BY1 and BY2 biosorption was estimated as 2.3, 1.7 and 2.6. The values of rate constant $k_{n}{ }^{\prime}$ ranged from 0.001 to $0.039\left[\mathrm{~min}^{-1}\right] /[\mu \mathrm{mol} / \mathrm{g}]^{1-\mathrm{n}}$. From the presented results it is evident that pseudo- $n$-order model provides a satisfactory description of biosorption experimental data compared to prediction by equation (1) and (2) (data not shown).

Table 1. Pseudo- $n$-order kinetics parameters for BG4, BY1 and BY2 sorption by $R$. squarrosus at $\mathrm{pH} 4$ and $25^{\circ} \mathrm{C}$ from aqueous solutions obtained by using non-linear regression analysis.

\begin{tabular}{|c|c|c|c|c|c|c|}
\hline Dye & $\begin{array}{c}C_{0} \\
{[\mu \mathrm{mol} / \mathrm{l}]}\end{array}$ & $\begin{array}{c}k_{n}^{\prime} \\
{\left[\mathrm{min}^{-1}\right] /[\mu \mathrm{mol} / \mathrm{g}]^{1-n}}\end{array}$ & $\begin{array}{c}Q_{\text {eq cal }} \\
{[\mu \mathrm{mol} / \mathrm{g}]} \\
\text { d.w. }\end{array}$ & $n$ & $R^{2}$ & $\begin{array}{c}Q_{\text {eq exp }} \\
{[\mu \mathrm{mol} / \mathrm{g}]} \\
\text { d.w. }\end{array}$ \\
\hline BG4 * & 122 & 0.014 & $65.0 \pm 0.3$ & 2.3 & 1.0 & 65 \\
\hline BY1 ** & 307 & 0.039 & $163 \pm 2$ & 1.7 & 0.998 & 168 \\
\hline $\mathrm{BY} 2 * *$ & 339 & 0.001 & $195 \pm 4$ & 2.6 & 0.996 & 195 \\
\hline
\end{tabular}

* Biosorbent concentration $=2.0 \mathrm{~g} / \mathrm{L}$

$* *$ Biosorbent concentration $=1.5 \mathrm{~g} / \mathrm{L}$

\subsection{Sorption equilibrium in single dye solutions}

Two well known adsorption isotherm models, namely Langmuir and Freundlich ones, were applied for the analysis of the experimental data (Table 2).

Table 2. Adsorption isotherm models for single sorption systems in linear and non-linear forms used in this work.

\begin{tabular}{lcc}
\hline \multicolumn{1}{c}{ Isotherm } & Non-linear form & Linear form \\
\hline Langmuir & $Q_{e q}=\frac{b Q_{\text {max }} C_{e q}}{1+b C_{e q}}$ & $\frac{C_{e q}}{Q_{e q}}=\frac{1}{Q_{\max }} C_{e q}+\frac{1}{b Q_{\max }}$ \\
Freundlich & $Q_{e q}=K C_{e q}^{(1 / n)}$ & $\log \left(Q_{e q}\right)=\log K+1 / n \log \left(C_{e q}\right)$ \\
\hline
\end{tabular}

These models use parameters that reflect the nature of the sorbent and can be used to compare biosorption performance. $Q_{\max }$ represents the maximum sorption capacity, $b$ is a constant related to the energy of adsorption. $k$ and $1 / n$ values are the Freundlich constants referring to adsorption capacity and intensity of adsorption, respectively. Simplicity and easy interpretability are some of the important reasons for the extensive use of these models. Moreover, linear regression has been frequently used to evaluate the model parameters. However, transformations of nonlinear equations into linear 
forms usually result in parameter estimation error and distort the fit (KUMAR and SIVANESAN, 2006). For this reason, nonlinear methods for parameters estimation were used in our work.

We have found, that sorption of cationic dyes BY1, BY2 and BG4 by $R$. squarrosus increased with the increasing concentration of dyes in solutions (data not shown) and the equilibrium was reached within 1-2 h. Figure 2 shows the experimental data fitted to the isotherm models for BY1, BY2 and BG4 sorption by $R$. squarrosus at $\mathrm{pH} 4$ from single dye solutions. The obtained adjustable parameters are shown in Table 3 with the corresponding coefficients of determination. Estimated maximum sorption capacity $Q_{\max }$ for BY1 biosorption obtained from Langmuir isotherm was $310 \pm 10 \mu \mathrm{mol} / \mathrm{g}$ d.w. (Table 3). The $Q_{\max } 382 \pm 11 \mu \mathrm{mol} / \mathrm{g} \mathrm{d}$.w. for BY2 was obtained. The maximum sorption capacity $Q_{\max }$ for BG4 biosorption obtained from Langmuir isotherm was $354 \pm 33 \mu \mathrm{mol} / \mathrm{g} \mathrm{d}$.w. This indicates a higher sorption capacity of $R$. squarrosus for BY2 in comparison with BY1 and BG4. Freundlich parameter $1 / n$ is the heterogeneity factor with the values ranged between $0-1$. If the value is close to unity this implies that sorption is chemical process. The more heterogenous the surface the closer $1 / n$ value is to 0 . In fact, for tested dyes the $1 / n$ values are close to 0 (Table 3 ).

The values of $R^{2}$ are generally regarded as a measure of the goodness of fit of experimental data on the isotherm models (Al-ASHEH et al., 2000; BASHA et al., 2008). As can be seen from Table 3 higher coefficients of determination $R^{2}$ were obtained for the Freundlich model $\left(R^{2}=0.983\right.$ for BY $1, R^{2}=0.976$ for BY $2, R^{2}=0.945$ for $\mathrm{BG} 4)$ compared to Langmuir isotherm $\left(R^{2}=0.906\right.$ for $\mathrm{BY} 1, R^{2}=0.947$ for $\mathrm{BY} 2, R^{2}$ $=0.789$ for BG4).

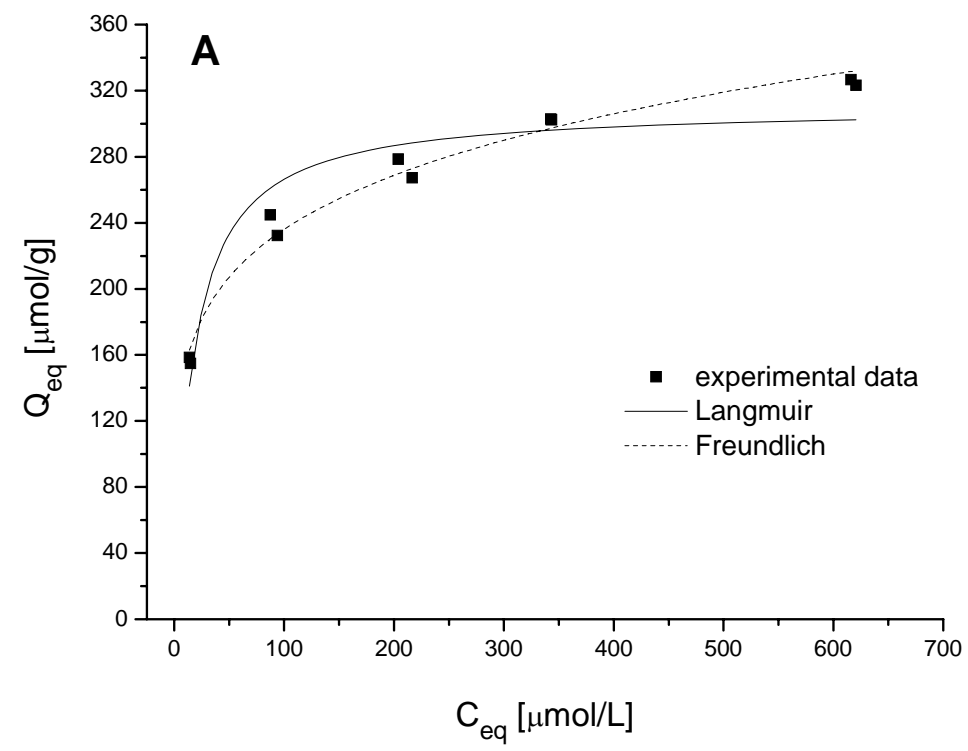



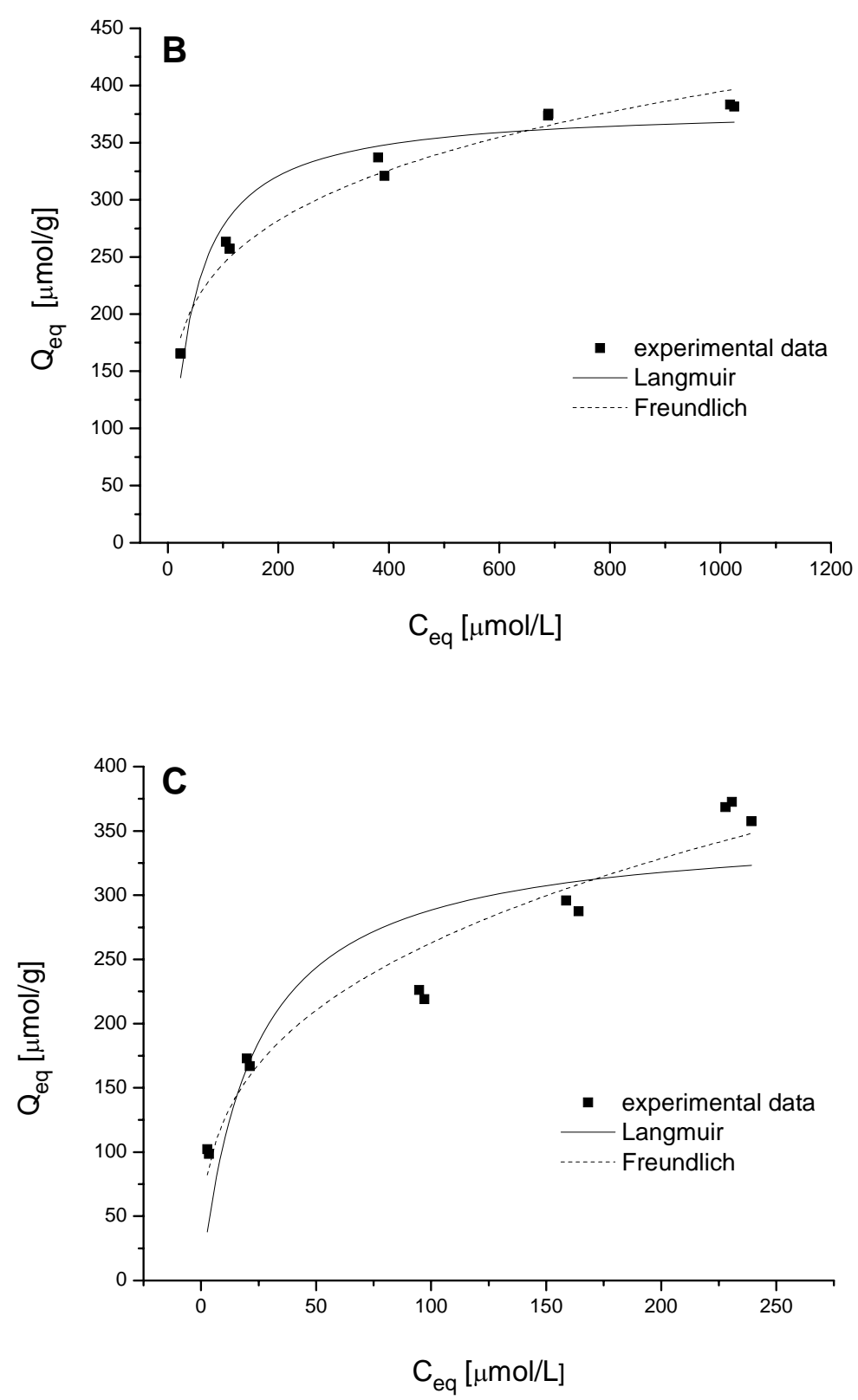

Fig. 2. Fit of the Langmuir and Freundlich adsorption isotherms of BY1 (A), BY2 (B) and BG4 (C) biosorption by $R$. squarrosus $\left(1.0 \mathrm{~g} / \mathrm{L}\right.$, d.w.) from single dye solutions at $25^{\circ} \mathrm{C}$ and initial $\mathrm{pH} 4.0$. Equilibrium $\mathrm{pH}$ 5.4. The corresponding data are shown in Table 3. 
Table 3. Adsorption isotherm models and corresponding parameters for BY1, BY2 and BG4 sorption by $R$.. squarrosus from single dye solutions at $\mathrm{pH} 4$ obtained by using non-linear regression analysis.

\begin{tabular}{|c|c|c|c|c|c|c|}
\hline Model & Dye & $\begin{array}{c}Q_{\max } \\
{[\mu \mathrm{mol} / \mathrm{g}] \text { d.w. }}\end{array}$ & $\begin{array}{c}b \\
{[\mathrm{~L} / \mu \mathrm{mol}]}\end{array}$ & $\begin{array}{c}K \\
{[\mathbf{L} / \mathbf{g}]}\end{array}$ & $1 / n$ & $R^{2}$ \\
\hline \multirow[t]{3}{*}{ Langmuir } & BY1 & $310 \pm 10$ & $0.06 \pm 0.01$ & - & - & 0.906 \\
\hline & BY2 & $382 \pm 11$ & $0.026 \pm 0.004$ & - & - & 0.947 \\
\hline & BG4 & $354 \pm 33$ & $0.04 \pm 0.02$ & - & - & 0.789 \\
\hline \multirow[t]{3}{*}{ Freundlich } & BY1 & - & - & $99.7 \pm 5.5$ & $0.19 \pm 0.01$ & 0.983 \\
\hline & BY2 & - & - & $93.2 \pm 7.7$ & $0.21 \pm 0.01$ & 0.976 \\
\hline & BG4 & - & - & $59.7 \pm 10.5$ & $0.32 \pm 0.04$ & 0.945 \\
\hline
\end{tabular}

This shows that the Freundlich isotherm is better fitted to the experimental data of BY1, BY2 and BG4 sorption by R. squarrosus in the concentration range studied and describes the process well and quantitatively. The Freundlich model provides a more realistic description of dye sorption by organic matter because it accounts for sorption to heterogeneous surfaces or surfaces supporting sites of varied affinity. However, we draw attention to some published papers stressing that the application of adsorption models is not able to explain the biosorption mechanisms of complex biological systems (FRAILE et al., 2005; CORDERO et al., 2004).

\section{Conclusions}

Sorption capability of biosorbent prepared from moss $R$. squarrosus was tested for cationic dyes BG4, BY1 and BY2 in batch experiments. The removal of dyes by moss biosorbent was found to be rapid at an initial stage and the equilibrium was reached within 1-2 hours. The kinetic analysis showed that biosorption process could be described well with the pseudo- $n$-order kinetic model. The respective reaction order for BG4, BY1 and BY2 biosorption was estimated as 2.3, 1.7 and 2.6. Equilibrium data were analysed using Langmuir and Freundlich isotherm models. The Freundlich isotherm was demonstrated to provide a very good correlation for the biosorption of BG4, BY1 and BY2 onto moss biosorbent.

\section{References}

AL-ASHEH, S., BANAT, F., AL-OMARI, R., DUVNJAK, Z.: Predictions of binary sorption isotherms for the sorption of heavy metals by pine bark using single isotherm data. Chemosphere, 41, 2000, 659-665.

AKSU, Z.: Application of biosorption for the removal of organic pollutants: a review. Process Biochem., 40, 2005, 997-1026. 
BASHA, S., MURTHY, Z.V.P., JHA, B.: Sorption of Hg (II) from aqueous solutions onto Carica papaya: Application of isotherms. Chem. Eng. J., 47, 2008, 980-986.

CORDERO, B., LODEIRO, P., HERRERO, R., SASTRE DE VICENTE, M.E.: Biosorption of cadmium by Fucus spinalis. Environ. Chem., 1, 2004, 180-187.

CRINI, G.: Kinetic and equilibrium studies on the removal of cationic dyes from aqueous solution by adsorption onto cyclodextrin polymer. Dyes Pigments, 2008, $77,415-426$.

CRINI, G.: Non-conventional low-cost adsorbents for dye removal: A review. Bioresour. Technol., 97, 2006, 1061-1085.

CRINI, G., BADOT, P.-M.: Application of chitosan, a natural aminopolysaccharide, for dye removal from aqueous solutions by adsorption processes using batch studies: A review of recent literature. Progr. Polymer Sci., 33, 2008, 399-447.

CRINI, G. PEINDY, H.N.: Adsorption of C.I. Basic blue 9 on cyclodextrin based material containing carboxylic groups. Dyes Pigment, 70, 2006, 204-211.

CRINI, G., PEINDY, H.N., GIMBERT, F., ROBERT, C.: Removal of C.I. Basic Green 4 (malachite green) from aqueous solutions by adsorption using cyclodextrin-based adsorbent: Kinetic and equilibrium studies. Sep. Purif. Technol., 53, 2007, 97-110.

FRAILE, A., PENCHE, S., GONZÁlES, F., BLÁZQUEZ, M.L., MUÑOZ, J. BALLESTER, A.: Biosorption of copper, zinc, cadmium and nickel by Chlorella vulgaris. Chem. Ecol., 21, 2005, 61-75.

HO, Y.S., NG, J.C.Y., McKAY, G.: Kinetics of pollutant sorption by biosorbents: Review. Separ. Purif. Meth., 29, 2000, 189-232.

INBARAJ, B.S., CHIEN, J.T., HO, G.H., YANG, J., CHEN, B.H.: Equilibrium and kinetic studies on sorption of basic dyes by a natural biopolymer poly $(\gamma$-glutamic acid). Biochem. Eng. J., 31, 2006, 204-215.

IQBAL, M.J., ASHIQ, M.N.: Adsorption of dyes from aqueous solutions on activated charcoal. J. Hazard. Mat., B 139, 2007, 57-66.

KUMAR, K.V., SIVANESAN, S.: Isotherm parameters for basic dyes onto activated carbon: Comparison of linear and nonlinear methods. J. Hazard. Mat., 129, 2006, 147-150.

LIU, Y., LIU, Y.J.: Biosorption isotherms, kinetics and thermodynamics. Sep. Purif. Technol., 61, 2008, p. 229-242.

LIU, Y., SHEN, L.: A general rate law equation for biosorption. Biochem. Eng. J., 38, 2008, 390-394.

LIU, Y., WANG, Z.W.: Uncertainity of preset-order kinetic equations in description of biosorption data. Bioresour. Technol., 99, 2008, 3309-3312.

ÖZER, A.: Removal of $\mathrm{Pb}(\mathrm{II})$ ions from aqueous solutions by sulphuric acid-treated wheat bran. J. Hazard. Mat., 141, 2007, 753-761. 